\title{
Anergy to dinitrochlorobenzene and depression of T-lymphocytes in Crohn's disease and ulcerative colitis
}

\author{
S. MEYERS, D. B. SACHAR ${ }^{1}$, R. N. TAUB, AND H. D. JANOWITZ \\ From the Divisions of Gastroenterology and Hematology of the Department of Medicine, The Mount \\ Sinai Hospital and the Mount Sinai School of Medicine, City University of New York, New York, USA
}

SUMMARY Skin reactivity to dinitrochlorobenzene (DNCB) and levels of circulating T-lymphocytes were measured in 15 patients with ulcerative colitis, 15 patients with Crohn's disease, and 12 normal control subjects. Diminished reactivity to DNCB was demonstrated in $87 \%$ of patients with Crohn's disease $(P<0.001)$ and in $53 \%$ with ulcerative colitis $(P<0.02)$, as compared with only $8.5 \%$ of controls; anergy was more frequent in Crohn's disease than in ulcerative colitis $(\mathrm{P}<0.05)$. Levels of circulating T-lymphocytes were also depressed in both Crohn's disease and ulcerative colitis $(\mathbf{P}<$ 0.001) as compared with controls, with the values lower in Crohn's disease than in ulcerative colitis (P < 0.02). There were no correlations of DNCB response with extent, duration, or severity of disease nor with T-cell levels within any patient group. These data provide further support for the concept that there is impairment of cell-mediated immunity among many patients with chronic inflammatory bowel disease, including both Crohn's disease and ulcerative colitis.

In recent years there has been increasing attention given to the integrity of cell-mediated immunity in patients with inflammatory bowel disease (Watson and Shorter, 1975; Janowitz and Sachar, 1976). In Crohn's disease, despite several studies suggesting normal cellular immunity (Binder et al., 1967; Fletcher and Hinton, 1967; Ropke, 1967; Bird and Britton, 1974; Bolton et al., 1974), most evidence to date indicates at least some degree of impairment of delayed hypersensitivity (Blackburn et al., 1939; Phear, 1958; Williams, 1965; Walker and Greaves, 1969; McHattie et al., 1971; Parent et al., 1971; Asquith et al., 1973; Guillou et al., 1973; Hunt and Trotter, 1973; Sachar et al., 1973). The status of the cellular immune response in ulcerative colitis has received less attention. Most previous studies have failed to demonstrate defects in the immune response in this disease (Binder et al., 1966; Hinz et al., 1967; Stefani and Fink, 1967; Parent et al., 1971; Aas et al., 1972; Asquith et al., 1973; Bolton et al., 1974). Data from our laboratory, however,

${ }^{1}$ Address for reprint requests: Dr David B. Sachar, Division of Gastroenterology, Mount Sinai School of Medicine, Annenberg, 23-02, New York 10029, USA.

Received for publication 28 June 1976 have indicated impaired lymphocyte responsiveness and diminished proportions and absolute counts of circulating T-cells in both Crohn's disease and ulcerative colitis (Sachar et al., 1973; Sachar et al., 1976). These differing conclusions prompted us further to evaluate cellular immunity in patients with Crohn's disease and ulcerative colitis by measuring both cutaneous reactivity to dinitrochlorobenzene (DNCB) and levels of circulating T-lymphocytes.

\section{Methods}

\section{PATIENTS}

We studied 15 patients with ulcerative colitis (UC) and 15 with Crohn's disease (CD). The duration of illness ranged from less than one year to more than 30 years. Two of the patients with ulcerative colitis had disease limited to the rectum alone, two to the rectum and sigmoid colon, and $\mathbf{1 0}$ to the left colon; one patient with universal colitis had had a total colectomy several years before the study. The Crohn's disease group consisted of seven patients with disease limited to distal ileum, five with ileocolitis, and three with only colonic disease. Crohn's colitis was distinguished from ulcerative colitis by 
the criteria of Lockhart-Mummery and Morson (1960), as outlined in our previous studies (Sachar et al., 1973; Greenstein et al., 1975).

Disease activity was classified as absent, moderate, or severe. In patients with Crohn's disease, 'absent' referred to those clinically well after bowel resection with no radiographic or proctoscopic evidence of disease; 'moderate' included those with radiographic and/or proctoscopic evidence of disease but in whom symptoms of abdominal pain and diarrhoea were minimal and fever, weight loss, abscess or fistula absent; 'severe' denoted those patients who had radiographic and/or proctoscopic evidence of disease with severe abdominal pain, diarrhoea, fever, weight loss, abscess, or fistula. In patients with ulcerative colitis, 'absent' disease meant previous total colectomy with a normally functioning ileostomy; 'moderate' included those patients with radiographic and/or proctoscopic evidence of disease but with minimal diarrhoea or rectal bleeding; 'severe', those with severe diarrhoea, pain, and rectal bleeding in addition to radiographic and/or proctoscopic evidence of disease. According to these criteria, the Crohn's disease group included three with absent, nine moderate, and three severe disease; and those with ulcerative colitis comprised one with absent, eight moderate, and six severe disease. Most patients were taking salicylazosulphapyridine at the time of study but had not received ACTH or corticosteroids nor undergone any surgery during the preceding month. None had received immunosuppressive therapy.

The normal control group (NC) consisted of 12 subjects who were all previously healthy with no apparent disease at the time of study. All groups were of similar age and sex distribution.

Before study, the research nature and possible adverse reactions of the DNCB skin test were fully discussed with the patients, who all gave informed consent.

\section{DNCB TESTING}

The method for DNCB testing was as described by Catalona et al. (1972). A sensitising dose of $2000 \mu \mathrm{g}$ DNCB in $0.1 \mathrm{ml}$ acetone was applied evenly over a circular area $2 \mathrm{~cm}$ in diameter on the volar surface of the forearm. The solvent was allowed to evaporate and the area covered with a dry dressing for 24 hours. A challenge dose of $100 \mu \mathrm{g}$ DNCB was applied 12 to 14 days later. A positive response consisted of induration and erythema at the test site 10 to 12 days after primary sensitisation or two to three days after secondary challenge.

BLOOD LYMPHOCYTE LEVELS

The peripheral lymphocyte count was calculated from total white blood count and differential smear. Lymphocytes were separated from heparinised peripheral venous blood by Ficoll-Hypaque sedimentation (Böyum, 1967), and washed thrice in minimal Eagle's medium containing $5 \%$ fetal calf serum. The number of T-lymphocytes was determined by counting the 'E-rosettes' formed with washed fresh unsensitised sheep erythrocytes using the method of Bentwich et al. (1973). The present Tcell studies represent a different series of measurements from those we have previously reported (Ramachandar et al., 1974; Sachar et al., 1976).

\section{STATISTICAL METHODS}

Analysis of significance was carried out using Student's $t$ test. Mean values are reported with standard error when indicated.

\section{Results}

\section{DNCB}

All subjects demonstrated a primary irritant response, manifested by erythema and frequently by itching and vesiculation. Delayed hypersensitivity was not considered to be present unless induration occurred. Anergy to DNCB was demonstrated in 13 of 15 patients with CD $(87 \%)$ and eight of 15 with UC $(53 \%)$, as compared with only one of 12 normal controls $(8 \cdot 5 \%)$. Anergy was thus significantly more

Table 1 Anergy to DNCB in Crohn's disease and ulcerative colitis

\begin{tabular}{llll}
\hline Diagnosis & $\begin{array}{l}\text { Number of } \\
\text { patients }\end{array}$ & \multicolumn{2}{l}{ With anergy } \\
\cline { 3 - 4 } & & $($ No.) & $(\%)$ \\
\hline Crohn's disease & 15 & 13 & $87^{*}$ \\
Ulcerative colitis & 15 & 8 & $53 \dagger$ \\
Normal controls & 12 & 1 & 8.5 \\
\hline
\end{tabular}

Significant difference from controls: ${ }^{*} \mathbf{P}<0.001, \dagger P<0.02$.

Table 2 Anergy to DNCB in different clinical categories of Crohn's disease

\begin{tabular}{lllr}
\hline Clinical category & $\begin{array}{l}\text { Number of } \\
\text { patients }\end{array}$ & \multicolumn{2}{l}{ With anergy } \\
\cline { 3 - 4 } & & $($ No.) & $(\%)$ \\
\hline Extent of disease & 7 & 6 & 86 \\
$\quad$ Terminal ileitis & 5 & 5 & 100 \\
Ileocolitis & 3 & 2 & 67 \\
Colitis & 3 & 2 & 67 \\
Activity of disease & 9 & 8 & 89 \\
Absent & 3 & 3 & 100 \\
Moderate & 2 & 2 & 100 \\
Severe & 3 & 1 & 33 \\
Duration of disease (yr) & 10 & 10 & 100 \\
Less than 1 & & & \\
1-5 & & & \\
Longer than 5 & & & \\
\hline
\end{tabular}


Table 3 Anergy to $D N C B$ in different clinical categories of ulcerative colitis

\begin{tabular}{llll}
\hline Clinical category & \multirow{2}{*}{$\begin{array}{l}\text { Number of } \\
\text { patients }\end{array}$} & \multicolumn{2}{l}{ With anergy } \\
\cline { 3 - 4 } & & $($ No. $)$ & $(\%)$ \\
\hline Extent of disease & 2 & 2 & 100 \\
$\quad$ Proctitis & 2 & 1 & 50 \\
$\quad$ Proctosigmoiditis & 10 & 4 & 40 \\
$\quad$ Left-sided colitis & 1 & 1 & 100 \\
$\quad$ Universal colitis & 1 & 1 & 100 \\
Activity of disease & 8 & 4 & 50 \\
$\quad$ Absent (post-colectomy) & 1 & 3 & 50 \\
$\quad$ Moderate & 6 & & 67 \\
Severe & 3 & 2 & 67 \\
Duration of disease (yr) & 6 & 3 & 50 \\
$\quad$ Less than 1 & 6 & 3 & 50 \\
1-5 & & & \\
$\quad$ Longer than 5 & & &
\end{tabular}

frequent than normal in both $\mathrm{CD}(\mathrm{P}<0.001)$ and UC $(P<0.02)$, with the incidence significantly higher in CD $(\mathrm{P}<0.05)$ (Table 1). There was no consistent correlation between DNCB response and extent, activity, or duration of disease (Tables 2, 3).

\section{LYMPHOCYTE LEVELS}

There were no significant differences in total lymphocyte counts among CD $(1818 \pm 173$ per cu $\mathrm{mm})$, UC $(1874 \pm 156)$, and NC(2335 \pm 176$)$. The T-lymphocyte counts for CD $(592 \pm 70)$ and UC $(851 \pm 80)$ were both significantly $(P<0.001)$ lower than NC $(1714 \pm 165)$, with CD lower than UC $(P<0.02)$ (Figure). Although DNCB-anergy and T-cell depression followed similar patterns (occurrence in $\mathrm{CD}<$ $\mathrm{UC}<\mathrm{NC}$ ), there was no correlation between impaired DNCB responses and low T-lymphocyte levels (defined as $<1100$ per cu mm), within each patient group (Table 4).

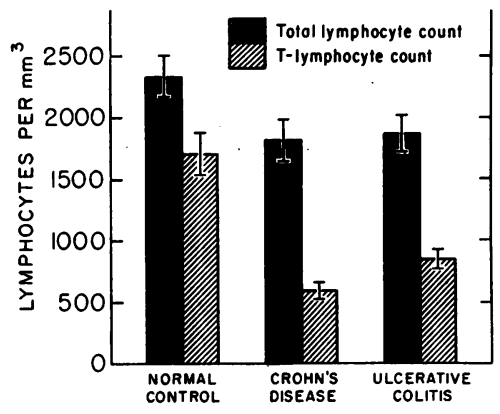

Figure Mean total and T-lymphocyte counts in Crohn's disease, ulcerative colitis, and normal controls. There are no significant differences in absolute counts among the three groups, but T-lymphocytes are significantly lower in both Crohn's disease and ulcerative colitis $(\mathrm{P}<0.001)$ than in controls. Depression of T-lymphocyte count is also greater in Crohn's disease than in ulcerative colitis $(\mathrm{P}<0.02)$.
Table $4 T$-lymphocyte counts and anergy to $D N C B$ in inflammatory bowel disease

\begin{tabular}{lccc}
\hline & $\begin{array}{c}\text { Number of } \\
\text { patients }\end{array}$ & \multicolumn{2}{c}{ With anergy } \\
\cline { 3 - 4 } & & $($ No. $)$ & $(\%)$ \\
\hline $\begin{array}{l}\text { Crohn's disease } \\
\text { Normal T-lymphocyte } \\
\quad \text { count }\end{array}$ & 2 & 2 & 100 \\
$\begin{array}{l}\text { Depressed T-lymphocyte } \\
\quad \text { count }\end{array}$ & 13 & 11 & 85 \\
$\begin{array}{l}\text { Total } \\
\text { Ulcerative colitis } \\
\quad \text { Normal T-lymphocyte } \\
\quad \text { count }\end{array}$ & 15 & 13 & 87 \\
$\begin{array}{l}\text { Depressed T-lymphocyte } \\
\text { count }\end{array}$ & 2 & & \\
Total & 13 & 1 & 50 \\
\hline & 15 & 7 & 54 \\
\hline
\end{tabular}

\section{Discussion}

The development of delayed cutaneous reactions to topically applied dinitrochlorobenzene has come to be accepted as evidence for intact cell-mediated immune function (Aisenberg, 1962). The increased frequency of anergy to DNCB which we have found in patients both with $\mathrm{UC}$ and with $\mathrm{CD}$ suggests some impairment of cell-mediated immunity in both of these diseases. This is in agreement with our previous findings of impaired lymphocyte responsiveness to phytohaemagglutinin (Sachar et al., 1973) and decreased proportions and absolute counts of circulating T-lymphocytes (Sachar et al., 1976).

A number of previous studies in patients with Crohn's disease have pointed to a moderate decrease in one or more indices of cellular immune function. The present finding of impaired DNCB responses, for example, agrees closely with the earlier data of Jones et al. (1969). Similarly, impaired lymphocyte response to phytohaemagglutinin has been reported in several studies of CD (Walker and Greaves, 1969; Brown et al., 1970; McHattie et al., 1971 ; Parent et al., 1971; Asquith et al., 1973), as have decreased levels of circulating T-lymphocytes (Strickland et al., 1974) and impaired cutaneous responsiveness to a broad spectrum of antigens (Meuwissen et al., 1975). These previous studies, like ours, have demonstrated no relationship between impaired immunity and the duration, extent, or severity of the bowel disease. More recent studies showing normal PHA responsiveness of lymphocytes in CD and UC (Bird and Britton, 1974; Bolton et al., 1974) were not carried out with a PHA dose-response curve and may not have been sufficiently sensitive. Bolton et al. (1974) have also reported 'normal' DNCB-reactivity in both $\mathrm{CD}$ and UC, but the DNCB-anergy rate in their control group was considerably higher than that in most other studies, which may have vitiated the significance of the high incidence of anergy observed in their patient groups. 
Our present and past observations of impaired cellular immunity in UC contrast with the conclusions of some other previous reports. Some possible technical reasons for apparent lack of impaired PHA-responsiveness in other studies (Hinz et al., 1967; Stefani and Fink, 1967; Parent et al., 1971; Aas et al., 1972; Asquith et al., 1973; Bolton et al., 1974) have been discussed by us previously (Sachar et al., 1973; Sachar and Taub, 1975). Other claims of normal cellular immunity in ulcerative colitis have been based upon results of conventional skin testing with mumps, coccidioidin, and trichophyton (Binder et al., 1966) as well as with tuberculin (Bolton et al., 1974). The discrepancy between these conventional skin tests and DNCB responses suggests that in inflammatory bowel disease there may be a defect in primary sensitisation to new antigens as opposed to the recall of sensitivities acquired before the onset of disease.

The functional and anatomical site and pathogenetic significance of the defect in cellular immunity seen in both ulcerative colitis and Crohn's disease remain unknown. It is possible that, in some cases, severe illness, malnutrition, or chronic intestinal transudation or sequestration of lymphocytes might contribute to defective cellular immunity. It appears unlikely, however, that these are the principal causative factors, since the impairments observed in the present and previous studies (Jones et al., 1969; Sachar et al., 1973; Strickland et al., 1974; Meuwissen et al., 1976) do not correlate with clinical severity, anatomical extent, or duration of disease, or with levels of circulating T-lymphocytes. Indeed, we have frequently noted anergy even in patients all of whose measurable disease had been long since surgically removed (Tables 2 and 3) or whose peripheral T-cell counts were normal (Table 4). It would now be important, therefore, to determine if the defect represents a secondary manifestation of some other unrecognised facet of inflammatory bowel disease, or a primary pathogenetic factor in susceptibility, or some independent genetic 'marker' of disease predisposition. Studies of relatives of patients with inflammatory bowel disease and of long-term postcolectomy ulcerative colitis patients are now under way in order to shed additional light on this question.

The authors thank Mr Steven Forman for technical assistance and $\mathrm{Mr}$ Richard Feinstein for assistance with data collection. We also thank Dr Leon Dixon, Col., MC (USA) for valuable advice throughout the study.

\section{References}

Aas, J., Huizenga, K. A., Newcomer, A. D., and Shorter,
R. G. (1972). Inflammatory bowel disease: lymphocytic responses to nonspecific stimulation in vitro. Scandinavian Journal of Gastroenterology, 7, 299-303.

Aisenberg, A. C. (1962). Studies on delayed hypersensitivity in Hodgkin's disease. Journal of Clinical Investigation, 41, 1964-1970.

Asquith, P., Kraft, S. C., and Rothberg, R. M. (1973). Lymphocyte responses to nonspecific mitogens in inflammatory bowel disease. Gastroenterology, 65, 1-7.

Bentwich, Z., Douglas, S. D., Siegal, F. P., and Kunkel, H. G. (1973). Human lymphocyte-sheep erythrocyte rosette formation: some characteristics of the interaction. Clinical and Immunological Immunopathology, 1, 511-522.

Binder, H. J., Spiro, H. M., and Thayer, W. R., Jr (1966). Delayed hypersensitivity in regional enteritis and ulcerative colitis. American Journal of Digestive Diseases, 11, 572-574.

Bird, A. G., and Britton, S. (1974). No evidence for decreased lymphocyte reactivity in Crohn's disease. Gastroenterology, 67, 926-932.

Blackburn, G., Hadfield, G., and Hunt, A. H. (1939). Regional ileitis. St. Bartholomew's Hospital Reports, 72, 181-224.

Bolton, P. M., James, S. L., Newcombe, R. G., Whitehead, R. H., and Hughes, L. E. (1974). The immune competence of patients with inflammatory bowel disease. Gut, 15, 213219.

Böyum, A. (1968). Isolation of mononuclear cells and granulocytes from human blood. Isolation of mononuclear cells by one centrifugation and of granulocytes by combining centrifugation and sedimentation at 1 g. Scandinavian Journal of Clinical and Laboratory Investigation, 21, 77-89.

Brown, S. M., Taub, R. N., Present, D. H., and Janowitz, H. D. (1970). Short-term lymphocyte cultures in regional enteritis. (Letter). Lancet, 1, 1112.

Catalona, W. J., Taylor, P. T., Rabson, A. S., and Chretien, P. B. (1972). A method for dinitrochlorobenzene contact sensitization. New England Journal of Medicine, 286, 399402.

Fletcher, J., and Hinton, J. M. (1967). Tuberculin sensitivity in Crohn's disease: a controlled study. Lancet, 2, 753-754.

Greenstein, A. J., Sachar, D. B., Pasternack, B. S., and Janowitz, H. D. (1975). Reoperation and recurrence in Crohn's colitis and ileocolitis: crude and cumulative rates. New England Journal of Medicine, 293, 685-690.

Guillou, P. J., Brennan, T. G., and Giles, G. R. (1973). Lymphocyte transformation in the mesenteric lymph nodes of patients with Crohn's disease. Gut, 14, 20-24.

Hinz, C. F., Jr, Perlmann, P., and Hammarström, S. (1967). Reactivity in vitro of lymphocytes from patients with ulcerative colitis. Journal of Laboratory and Clinical Medicine, 70, 752-759.

Hunt, P. S., and Trotter, S. (1973). Lymphoblastic response to autologous colon epithelial cells in ulcerative colitis in vitro. Gut, 14, 875-879.

Janowitz, H. D., and Sachar, D. B. (1976). New observations in Crohn's disease. Annual Review of Medicine, 27, 269285.

Jones, J. V., Housley, J., Ashurst, P. M., and Hawkins, C. F. (1969). Development of delayed hypersensitivity to dinitrochlorobenzene in patients with Crohn's disease. Gut, 10, $52-56$.

Lockhart-Mummery, H. E., and Morson, B. C. (1960). Crohn's disease (regional enteritis) of the large intestine and its distinction from ulcerative colitis. Gut, 1, 87-105.

McHattie, J., Magil, A., Jeejeebbhoy, K., and Falk, R. E. (1971). Immunoresponsiveness of lymphocytes from patients with regional ileocolitis (Crohn's disease) by in vitro testing (Abstract). Clinical Research, 19, 779.

Meuwissen, S. G. M., Schellekens, P. T. A., Huismans, L., 
and Tytgat, G. N. (1975). Impaired anamnestic cellular immune response in patients with Crohn's disease. Gut, 16, 854-860.

Parent, K., Barrett, J., and Wilson, I. D. (1971). Investigation of the pathogenic mechanisms in regional enteritis with in vitro lymphocyte cultures. Gastroenterology, 61, 431-439.

Phear, D. M. (1958). The relation between regional ileitis and sarcoidosis. Lancet, 2, 1250-1251.

Ramachandar, K., Sachar, D. B., Janowitz, H. D., Forman, S. P., Douglas, S. D., and Taub, R. N. (1974). B-lymphocytes in inflammatory bowel disease. Lancet, 1, 45-46.

Röpke, C. (1972). Lymphocyte transformation and delayed hypersensitivity in Crohn's disease. Scandinavian Journal of Gastroenterology, 7, 671-677.

Sachar, D. B., and Taub, R. M. (1975). Lymphocyte responsiveness in inflammatory bowel disease. (Letter). Gastroenterology, 68, 1328-1329.

Sachar, D. B., Taub, R. N., Brown, S. M., Present, D. H. Korelitz, B. I., and Janowitz, H. D. (1973). Impaired lymphocyte responsiveness in inflammatory bowel disease. Gastroenterology, 64, 203-209.

Sachar, D. B., Taub, R. N., Ramachandar, K., Meyers, S.,
Forman, S. P., Douglas, S. D., and Janowitz, H. D. (1976). $\mathrm{T}$ - and B-lymphocytes and cutaneous anergy in inflammatory bowel disease. Annals of the New York Academy of Sciences, 278, 565-572.

Stefani, S., and Fink, S. (1967). Effect of E. coli antigens, tuberculin and phytohaemagglutinin upon ulcerative colitis lymphocytes. Gut, 8, 249-252.

Strickland, R. G., Korsmeyer, S., Soltis, R. D., Wilson, I. D., and Williams, R. C., Jr (1974). Peripheral blood T and B cells in chronic inflammatory bowel disease. Gastroenterology, 67, 569-577.

Walker, J. G., and Greaves, M. F. (1969). Delayed hypersensitivity and lymphocyte transformation in Crohn's disease and proctocolitis. (Abstract). Gut, 10, 414.

Watson, D. W., and Shorter, R. G. (1975). The immunology of ulcerative colitis and Crohn's disease: cell-mediated immune responses. In Inflammatory Bowel Disease, pp. 8198. Edited by J. B. Kirsner and R. G. Shorter. Lea and Febiger: Philadelphia.

Williams, W. J. (1965). A study of Crohn's syndrome using tissue extracts and the Kreim and Mantoux tests. Gut, 6 , 503-505. 